\title{
Shared Near-Death and Related Illness Experiences: Steps on an Unscheduled Journey
}

\author{
Glennys Howarth, Ph.D. \\ University of Bath, Bath, England \\ Allan Kellehear, Ph.D. \\ La Trobe University, Melbourne, Australia
}

\begin{abstract}
This paper discusses the key social features in shared journeys into near-death experiences (NDEs) and related illness experiences of other people. Of special interest in this paper is the way that those persons who are not ill or near death account for their sharing of these experiences. These are often people who are caregivers or intimates of NDErs or dying people but who claim to share part of the NDE or dying experience. We provide case examples to illustrate the essential psychological and social experiences that these people undergo during their joint experiences with NDErs and other seriously ill people. From an analysis of the recurrent themes emergent in these joint experiences we identify and discuss the major conceptual steps in the creation of their personal explanations: (1) Exit the Familiar, (2) Extraordinary Experiences, (3) Extraordinary Experiences End, (4) What Happened to Me? (5) The World Responds, and (6) The Return of the Native. In the final analysis, the processes that these people undergo in the search for explanations is similar in most respects to those at the center of near-death and other related illness experiences.
\end{abstract}

KEY WORDS: near-death experiences; empathy; illness; dying; social reintegration.

Glennys Howarth, Ph.D., is Reader in Sociology at the University of Bath, UK. Allan Kellehear, Ph.D., is Professor of Palliative Care at La Trobe University, Australia. The authors wish to acknowledge the generous assistance of Willis Poynton at the Society for Psychical Research in London; The Alister Hardy Trust at Westminster College in Oxford, UK, and especially the Director, Peggy Morgan; and the British Academy for a British Academy Visiting Professorship enabling Dr. Kellehear to collect data, to travel, and to work with Dr. Howarth on the research for this paper. Reprint requests should be addressed to Professor Kellehear, Palliative Care Unit, La Trobe University, 215 Franklin Street, Melbourne, 3000, Australia; e-mail: A.Kellehear@latrobe.edu.au. 
Unusual experiences in life always demand explanation. Accidents, illnesses, and job loss are all events that disrupt the taken-for-granted cycles of everyday life. These experiences, indeed all experiences, do not in themselves suggest explanations. Often, people look to a variety of sources for information to help them make sense of these unusual occurrences in their lives. For example, in sudden and severe illness situations the physical symptoms and the emotional stress provide only minimal information for the person at the center of the experience. In the task of making sense of what is happening to them they will often look to other people and their opinions and advice to help construct personal theories about causes and consequences. How much more so for people who share in near-death experiences (NDEs)?

Although rarely reported in the near-death studies literature, there have been a number of important cases of people who have "shared near-death experiences and visions." Raymond Moody called these experiences "empathic NDEs," "conjoint NDEs," or "mutual NDEs" $(1999$, p. 4$)$. In these experiences, which occur commonly to people who are caring for dying persons, the experiencers report sharing some of the actual near-death phenomenology, such as experiences of bright light, out-of-body experiences (OBEs), meeting supernatural or deceased beings, tunnel sensations, or enjoying experiences of peace or joy.

The processes by which these people arrive at their particular personal and social explanations of their remarkable experiences, particularly since they themselves are not ill or near death, are rarely discussed in the NDE literature. This paper will address this omission by examining the key characteristics of shared near-death and related experiences and developing a theoretical model of how these people come to their private and public explanations about these experiences. First, we will identify and examine key shared neardeath and related illness experiences. Secondly, we will compare and contrast the processes of explanation construction in each, identifying important recurring themes that appear in these processes. Finally, we will identify and discuss the core steps in explanation construction, as well as any variants, as these emerge from the preceding analysis of the themes.

\section{Shared Near-Death and Related Illness Experiences}

There are three key shared near-death and related illness experiences: (1) shared near-death visions; (2) shared near-death experiences; 
and (3) shared experiences of illness, particularly illness experiences from remote locations.

\section{Shared Near-Death Visions}

Peter Fenwick and Elizabeth Fenwick (1995) reported our first case. As a daughter sat beside her mother's deathbed, the daughter experienced what she reported as a "vision." She claimed that this was not her "imagination running riot" or a dream (pp. 252-253). During her vision she saw a beautiful garden and hillside from which she saw a dead aunt holding out her hands to her dying mother. The mother and aunt met and went away together. In this particular case the experiencer reported that her experience was a comforting vision and resisted the idea that she were dreaming or imagining the event.

Near-death visions that are experienced by the dying person's companions are not entirely new. In $1908 \mathrm{O}$. O. Burgess reported a case of a man who experienced unusual visions during the deathwatch over his dying wife. During the course of some five hours at the bedside of his wife the husband experienced extreme drowsiness and a feeling of being "heavy limbed." He witnessed visions of several "smoky" beings who came to attend upon his unconscious wife. At first he believed the "beings" were wafts of cigarette smoke, but after determining that there was no actual smoke his attention refocused on the smoky figures.

These figures lingered about his wife's bedside. Shortly before the actual death of his wife a figure of a woman materialized above his wife's head. This was surrounded by other white figures apparently leaning towards the female figure. The female figure moved about in a struggling fashion, stretching out its arms in an effort to free itself, and then came to rest for a period, only to resume its inexplicable struggle again sometime later. When finally his wife breathed her last breath the figure struggled once more and an ethereal connection between the figure and his wife became severed. At this point all the figures seemed to disappear (Burgess, 1908).

In 1926 William Barrett reported the case of another death vigil undertaken by three nieces and the housekeeper of a dying woman. In this case the near-death vision was quite clearly "shared." During the evening before the woman's actual death all three of her nieces witnessed the figure of the dying woman's deceased sister walking through the house. The dying woman confessed that she had also seen her deceased sister that evening saying that "her sister had come for her, for she had seen her" (Barrett, 1986/1926, pp. 35-36). 
More recently, Karlis Osis (1961) reported the case of a nurse and a patient who both saw a vision of the patient's dead sister. In another case a nurse at the bedside of her dying husband reported seeing "people dressed like they did at Christ's time, fade through the wall" (p. 76). The husband later reported the identical scene to her nurse wife before dying.

In these above cases of shared near-death visions each participant was engaged in a death watch with the dying person. The situation is unusual but not abnormal, and undoubtedly stressful for the caregivers. The normal cycles of work and recreation are interrupted when someone assumes the role of caregiver for a dying relative. This is a crisis in the family, a time of loss and separation from one's usual attachments and relationships. This loss and separation apply both to the relationship with the dying person and also to one's usual social life and activities during the care period.

Features of near-death visions that are reported by some dying persons are here reported instead by their caregivers, or by both the caregivers and the dying person: bright lights, encounters with deceased beings, or beautiful vistas in another world. At the completion of the experience the search for explanations begins. What did the caregiver actually experience, actually see? In each of the cases above the caregiver carefully insisted on differentiating his or her experience from delusions or dreams. Indeed in the 1908 case, the caregiver was so startled by his experience that he sought reassurance from others in the house that he was not losing his mind. He feared for his sanity. In the throes of that anxiety he sought out the family doctor, who reassured him of his psychological health.

As with so many reports from NDErs themselves, the choices of explanation appear to be madness, hallucinations, or the possibility of actual perceptions of another reality. Conclusions about these options are frequently reached by discussing the possibilities with others, although, of course, they may not. Some people rehearse the possible explanations by privately reflecting on social sources of information such as radio or television programs, newspaper stories, books, or religious teachings. In all these ways, people who share near-death visions find themselves in the same social dilemma and tensions as those of NDErs themselves, particularly when confronting the task of telling others.

The task of reintegrating themselves back into their societies and usual company is therefore dependent first on the type and variety of 
feedback that they obtain about their unusual experiences and secondly on the content of the story that they tell others. Overall, people who share near-death visions experience a period of social separation, a period of unusual social and psychological experience, a desperate need to explain that experience, a desire for information and feedback to help them to satisfy that need, and finally a reintegration back into their usual company and cycles of life armed with one or more versions of an explanation.

\section{Shared Near-Death Experiences}

Although far less commonly reported, there have been documented cases of shared near-death experiences. Fenwick and Fenwick (1995) described two such cases. In the first case, adult children were present at the dying bedside of their father. A speck of light appeared on the wall opposite the father's bed, darting about the wall. Everyone in the room saw this light, including the father, who was sitting in the bed propped up by pillows. After a while the wall itself changed color and became very bright, where previously it had been somewhat dark:

Then a figure appeared on the wall. It looked like a monk, someone with a long cloak which covered the head and face. At this I went and stood at the end of the bed. Within a short time my mother, sister, brother, could all see a mist forming from my head down the right side of my body, as if the figure that was behind me was not a big person and I was in the way. My sister came up to me and ran her fingers between the mist and me. She kept saying, 'Who is it, Dad, who is it?'.. I went across to touch my dad's hand but he just lifted himself and pushed me away. I tried again but this time he was really mad and gave a fierce shout at me... he waved his hands as if to say, get out, go away. (Fenwick and Fenwick, 1995, p. 251)

Not long after this incident the father died.

In the second case of shared NDEs, Fenwick and Fenwick described a woman who sat with her dying sister. At some point before actually dying, the ill woman attempted to tell her sister about something that she saw. As she began her description the sisters realized that they could both see and experience the events that had captured their combined attention:

I could see this beautiful gold light at the end of a tunnel; she agreed, so I held her hand and down we went together. She was afraid but I told her it was all right, I was with her and I wasn't afraid. It seemed as though we were almost floating but the main thing was the light 
at the end of the tunnel was getting bigger and brighter. We traveled on and then all of a sudden it seemed as if I went into a plate glass window but looking across at my sister she just went through into the garden. She looked back at me and called me and said our gran was there. I could see a few of my relatives around the edge of the garden, which was raised ground with a white fence around. The people were on the other side. The flowers were beautiful and the grass reflected the gold from the sunshine. My sister was standing with her arms up above her head, turning around in circles and calling me to come. I said I can't, they won't let me through. (Fenwick and Fenwick, 1995, pp. 251-252)

At that point, the well sister returned to her body and gazed at her dying sister, who was now quiet. Some hours later the ill sister died.

From the archives of the Religious Experience Research Centre at the Alister Hardy Trust, Westminster College, Oxford, England, comes one other account of a participant in another person's NDE (unpublished case record \#2015). As a woman lay seriously ill in isolation in an infectious disease hospital she suddenly had an out-of-body experience. She described floating "on a comfortable cloud somewhere above my bed." As she began to consider floating further away on her journey she heard a voice pleading, "Don't go yet, I haven't finished; you can't go yet."

In response to this request she returned to her body, and after recovery was surprised to learn that the voice was not from "the other side" but from a child she had befriended in a bed close to her own. She had been reading children's stories to this little boy for some time. As the boy watched the woman, his reading companion, become more and more ill, he asked God if He would let the woman stay a little longer, "cos I hadn't finished the story of the Floppsy Bunnies." God reportedly told the boy to ask the woman himself. This he did, and the woman heard his voice inside her NDE, influencing her decision to return.

These cases of shared NDEs resemble cases of shared near-death visions. The social circumstances of separation are identical; most of the participants were involved in bedside vigils with dying relatives or friends. In the cases of shared NDEs, parts of the NDE of the dying person are entered or shared by their companions: OBEs, bright lights, encounters with supernatural beings or deceased relatives, and visions of supernatural vistas of physical beauty. The one important difference between shared near-death visions and shared NDEs is that there is not necessarily any corroborative feedback from the dying person in shared near-death visions. In cases of shared near-death visions the 
dying person eventually dies, and usually quite soon after the vision, and the surviving participant is subsequently left to his or her own devices to piece together an understanding of what has happened.

In the shared NDE cases the NDE is a fellow traveler and is able to interact and confirm the joint experiences. Joint NDErs and NDErs are always able to communicate with one another and affirm one another's experiences. That shared communication reinforces a conviction of a shared reality, which privileges a survival rather than a simple psychiatric or imaginary explanation. Feedback is immediate in shared NDEs and the explanation is often more confidently embraced, particularly since rechecking and comparison of notes is possible for some time afterwards. In shared near-death visions feedback may be delayed and often uncertain, since there is not necessarily any immediate feedback, or if there is, that person may die quickly after. This forecloses on the possibility of rechecking the story at a later time when the caregiver might question the veracity of his or her earlier experiences.

\section{Shared Illness Experiences}

We must not think that shared near-death visions or shared NDEs are the only experiences with the power to include others, a power associated solely with the experience of death. Death and near-death experiences are not the only events with the power to include temporary companions on the journey. Shared illness experiences have also been reported in the parapsychological literature, which suggests that shared experiences of illness and death may be related. In Edmund Gurney, Frederic Myers, and Frank Podmore's famous 1886 work Phantasms of the Living at least four cases of shared illness experiences were reported.

In the first case (case \#70) Gurney, Myers, and Podmore (1886) reported a woman who inexplicable fell ill while alone writing letters. She felt faint and desperately ill but could not account for why. She was helped by servants to a resting place and waited for her husband to return from work. It then occurred to her that her husband was actually late, and wondered whether anything terrible had befallen him. Eventually he did return home, but did so escorted by a companion from work. He too was severely ill, and when sufficiently recovered reported that although feeling ill most of the day his condition had taken a turn for the worst just before leaving time. The time that his physical condition worsened correlated perfectly with the onset of 
his wife's symptoms, which, incidentally, cleared on the arrival of her husband (Gurney, Myers, and Podmore, 1886, p. 273).

In the second case (case \#74) a woman became unaccountably ill and restless during her husband's absence in another city. She became so restless that she had to leave the house and take a carriage ride for several hours, something she disclosed to be an activity that she would never normally do. She later learned that her husband had had a stroke and lay delirious in a hotel room in Paris. She later learned that the timing of his illness and symptoms coincided with her own (Gurney, Myers, and Podmore, 1886, p. 277).

Laura Dale (1952) reported a further intriguing case of a woman who woke in the middle of the night with a sharp pain in her right hand and arm. Returning home from downtown the next afternoon, she discovered her son had returned home unexpectedly. He had been in an accident and had cut his right hand quite badly and had been sent home. The mother reported that: "On comparing notes, we found that the time element was the same" (p. 34).

Dale noted that this case was in many ways similar to one reported by Gurney, Myers, and Podmore (1886). In their case \#17, which Dale reprinted, a woman awakened one morning with a distinct impression that she had received a hard blow to the mouth and was bleeding from the lips. But as she dabbed her handkerchief to her mouth, she found that she was mistaken and that there was no such laceration or bleeding. Later on she learned from her husband, who had been out sailing, that he had received a sharp blow to the mouth from the tiller of his boat, this accident having occurred at about the same time her vivid impression aroused her from sleep (Dale, 1952, p. 35, citing Gurney, Myers, and Podmore, 1886, p. 188).

In each of these shared illness experiences the symptomatology of each experiencer accorded with the other, as indeed did the timing of their injuries or symptoms. In all cases, the person who shared the symptoms or injuries did not know how to explain the sensations, for those persons were otherwise well, or the onset was so sudden and sickening that they may have believed themselves on the brink of their own developing illness. Because the person who was really ill was in a remote location at quite a distance from the person sharing the experience, it is only when they met that they could compare notes. The vital information and feedback that would allow some arbitration over competing explanations was delayed, although when it arrived, the information about timing was frequently impressive. 
As with shared near-death visions or shared NDEs there are always competing explanations for shared illnesses. One of the strongest explanations competing for attention is simple coincidence. Sensations of pain and illness may be so frequent for all sorts of idiopathic reasons that it is inevitable that some of these might coincide with other people's actual illness experiences. Another possibility, not exclusive to the first, is that such events are fanciful and that both parties enjoy vivid imaginations. Finally, one might consider the role of telepathic connections between certain people, particularly family members or people with close bonds. In this explanatory scenario, emotional and motor effects of telepathic or clairvoyant relations appear to the persons involved to be the more convincing theory. Usually, the precise accordance of one person's symptoms or injuries, the timing, and their bodily locations, persuade the different parties of the strength of one explanation over another. Nevertheless, similar to shared NDEs but commonly dissimilar to shared near-death visions, the swapping and corroboration of the joint experiences is often vital to the ongoing construction of joint explanation.

\section{Six Steps on an Unscheduled Journey}

In the following discussion we approach the shared near-death vision, shared near-death experience, or shared illness experience as forms of status passage (Glaser and Strauss, 1971; Kellehear, 1990, 1996). In this context the concept of status passage identifies the change in status that results in a transitional journey from one social role to another. This journey inevitably involves a separation from a particular status, a period of instability or liminality, and finally a reintegration into a new status. Status passages may be scheduled and accompanied by readily understood social rituals, such as the passage from childhood to adulthood, or they may be unscheduled, leaving people to search for their own meaning or way of understanding the transition and new status identity.

Barney Glaser and Anselm Strauss (1971) argued that in contemporary western cultures, dying is an unscheduled status passage in that it is usually undesirable and involuntary and is only rarely accompanied by prescribed social rituals. Allan Kellehear (1990) took this analysis further by identifying NDEs as unscheduled status passages. They too are unexpected and involuntary and usually precipitated by 
undesirable circumstances. There are no socially prescribed rituals or processes to facilitate an understanding of the transition experience and new status. Indeed, according to Kellehear, what makes NDEs strikingly similar to dying as an unscheduled status passage is the marked lack of established social rituals to guide people through this transition experience. Moreover, unlike scheduled status passages, the NDE is socially stigmatized and subject to public explanations that seek to undermine their very existence.

Here we adopt this same approach in a theoretical analysis of status passage transition for people who share near-death visions, NDEs, and illness experiences. Like dying and NDEs, these experiences remove or separate the persons from their normal social situation and status. The persons are projected into a state of transition or liminality from whence they must reintegrate into their social world and make sense of their new social status. This reintegration requires the production of a credible explanation to enable the person to reestablish order and social acceptance in his or her personal reflections and social interactions. As we describe below, those who share these types of experiences may find it necessary to subscribe to two separate explanations: a public explanation that allows them to reintegrate into their social world, and a private explanation that enables them to make sense of their personal experience.

To explore the way in which these social processes are constructed we need to consider in turn the six steps that comprise the status passage experience. These steps are: (1) Exit the Familiar, (2) Extraordinary Experiences, (3) Extraordinary Experiences End, (4) What Happened to Me? (5) The World Responds, and (6) The Return of the Native.

\section{Exit the Familiar}

As we noted above, in cases of shared near-death visions and shared near-death experiences the people who share the experience are engaged in behavior that is out of the usual run of things. A deathwatch does not occur in the normal round of social life. Caring for a dying relative or close friend is an unusual undertaking that not only suspends most routine daily activities but also places caregivers in an exceptional psychological and social condition. Similarly, the sudden and unexpected onset of severe illness wrenches affected persons from the taken-for-granted world that surrounds them and from their status as healthy people. For those who share illness experiences the suddenness and utter inexplicability of the trauma they 
are experiencing exacerbates the distress and the shocking departure from the normal and unfamiliar.

\section{Extraordinary Experiences}

The experiences of those who share near-death or illness events are remarkable. Sharing near-death visions or near-death experiences involves encounters with supernatural beings, deceased friends or relatives, and bright lights; out-of-body and tunnel sensations; and extraordinary feelings of happiness. Those who share illness may experience inexplicable pain, distress, discomfort, or delirium. The event can alter both their physical and mental state, lasting for short or longer periods. It may instill a sense of horror or foreboding or require people to behave in singularly uncharacteristic and thus particularly disturbing ways, especially demanding of an explanation. In other words, these are illness events that are unrelated to the ordinary logic of daily life in which they perceive themselves as healthy people. These experiences cannot, for example, be traced back to an actual occurrence, such as a blow to the mouth, or to any earlier risk behavior, such as food poisoning.

\section{Extraordinary Experiences End}

Often, as suddenly as they begin, these extraordinary experiences end. There is frequently no warning or other mechanism to alert the person sharing a near-death vision or experience that the encounter is about to end. Indeed, the end itself may be shocking, as in the case of the woman described by Fenwick and Fenwick (1995) who shared her dying sister's NDE:

My sister was standing with her arms up above her head, turning around in circles and calling me to come. I said I can't, they won't let me through. With that it was almost like a gust of wind took me backwards and the next thing I knew with a big thud my body started to move. (p. 252)

In shared illness situations the experience may be short-lived, as in cases of acute pain, or may linger for a much longer period only to end as inexplicably as it began, returning the person to full health. Irrespective, however, of whether these experiences are shared neardeath visions, shared near-death experiences, or shared illness experiences, the return to normality is not the comfortable, unquestioning 
return to the familiar social world. It is a homecoming that demands an explanation.

\section{What Happened to $\mathrm{Me}$ ?}

If the person sharing such experiences is to make sense of them, for him or herself and for others, a plausible explanation is crucial to this step. The person needs to establish the experience as real rather than unreal. Failure to do so results in an incomplete status passage. Without the public and private recognition of the status transition that this enables, he or she is socially and psychologically suspended in a stigmatized explanatory world of hallucination and madness. Credible explanations that facilitate social acceptance and reintegration will be created from a series of private reflections that are either immediately or later mediated by the opinion and information input of others.

In broad terms, answers to the question as to what has happened to them fall into four categories. There are medical explanations of illness, stress, or madness; religious explanations, perhaps involving God or the devil; parapsychological explanations of survival or telepathy; and social explanations of coincidence. People who share near-death visions, NDEs, and illness experience use evidence, for example from the timing of events, witness accounts, and corroboration, to negotiate their way towards an explanation. The nature of this process will depend on a careful and deliberate telling of the nature of the experience, the extent and timing of feedback, the available evidence, and the testimonies of witnesses. That deliberation is the social method used to arbitrate between competing explanations.

\section{The World Responds}

For the person seeking a public or a private explanation, the responses of others are crucial to the social construction of understanding, and thereby, the social affirmation of completed status passage. However, it is important to emphasize here that "responses of others" does not necessarily mean interpersonal responses. Possible social responses, based on a range of attitudes in society, are also a part of one's internal socialization. These attitudes from others will be rehearsed intrapsychically as social responses.

People who have experienced shared near-death visions have a largely solitary task ahead of them in making sense of their encounter. 
The person with whom they shared the experience is commonly unable to provide them with any feedback or to participate in the social construction of an explanation. In contrast, shared near-death experiencers receive immediate feedback from their partner and thus are able to engage in the negotiation of an explanation. In so doing, the shared NDEr is more likely than the shared near-death visionary to settle for an explanation that privileges parapsychological or religious accounts. The near-death visionary, on the other hand, has fewer defenses again skeptical accounts that render the experience incredible.

The situation of the person returning from a shared illness experience is also quite distinct. Those sharing illness encounters are entirely reliant on witness accounts even before they can begin to ask, let alone answer, the question as to what has happened to them. Shared illness experiences occur remotely from the ill person. Although the experience is disconcerting and sometimes shocking, the only possible framework for explaining the experience is a medical one. Immediately following the experience people may consider themselves to have either been, or about to become, ill. For example, Gurney, Myers and Podmore (1886) reported the case (\#391) of a man who shared an illness experience with a close friend: "He could by no means account for it... He thought he must be sickening for a bad illness" (pp. 371-372).

There is no framework, other than a medical one, for making sense of the experience until it is corroborated by accounts of the illness of the other person. In other words, the experience does not become a shared illness experience until the world responds; that is, until the person is aware that he or she has a partner in the illness. Receipt of this delayed feedback effectively transforms the event from illness to a shared illness of a most unique kind, from a relatively mundane to an extraordinary experience, and, moreover, to an exceptional experience that demands a plausible explanation.

\section{The Return of the Native}

In making sense of these experiences people may arrive at two potentially distinct explanations: a private explanation and a public one. These explanations are designed to address different problems, both private and social. Indeed, the private explanation may sometimes be fundamentally at odds with the public one: the former is constructed for the private world of personal reflection, whereas the latter is produced specifically for the telling, the successful achievement of which will result in social acceptance. 
If the person sharing a near-death vision, $\mathrm{NDE}$, or illness experience is to reintegrate into the social world, he or she must choose a public explanation that is social acceptable. The primary criterion at this step, then, is to arrive at an explanation that is credible to others, which requires an assessment of the social audience. This is achieved through negotiation with those immediately involved in the experience, such as experience partners, but also in conjunction with other members of the social circle, and possibly also with medical and religious professionals.

Social explanations are essentially public stories and as such they need to be more flexible than private explanation. There are a range of potential public stories; example may include "It did not happen to me," "This was a strange coincidence," I think there is life after death; let me tell you what happened to me," or "I have a story I cannot explain." These kinds of public stories may change according to the nature of the audience and the certainty with which the audience hold their own beliefs about the particular types of appropriate social explanations for such experiences.

\section{Conclusion}

There are four observations to make about the preceding discussion. First, these steps are similar to those required of NDErs themselves (Kellehear, 1990). However, as the case material in this paper demonstrates, we need to recognize that occasionally NDErs and neardeath visionaries take temporary "passengers" or companions on part of their journey. This is important to recognize because so much of our previous empirical research, theoretical focus, and professional support responses have been toward NDErs and near-death visionaries, but we now know that other people may be involved in these experiences. Their infrequent presence and recent recognition raise interesting theoretical and research questions for the future.

Secondly, the problem of NDEs and near-death visions and shared experiences of both might be part of a larger experience of unusual illnesses and shared illness experiences. Although the problem of social rejection, stigma, and reintegration into the community is a wider problem of anyone with unusual religious, sexual, or social experiences, the company that these people keep are not always involved. We now have some early indications that people who accompany NDErs or neardeath visionaries do share some of their problems. This may mean that we need to view NDErs and their networks as part of the problem 
of society's tolerance and treatment of deviance and marginality, notwithstanding the more positive attitude recently observed around transcendental experiences.

Thirdly, for clinical and religious authorities, this may mean a review of their attitudes of and responses to social and cultural differences. They need to understand that trust and safety are interpersonal qualities that emerge from a "politics of knowledge": experiencers negotiate their trust and safety with strangers cautiously and conditionally. It is important to remember that there is no single attitude toward social diversity and difference in society, and that few people are comfortable psychologically or socially with unusual personal experiences. This discomfort comes from social uncertainty about other people's responses and the stereotypes that each of us holds about powerful others such as doctors or employers.

Finally, attention to the sociological dimensions of an unscheduled journey into strange places permits us to see that it is not merely or solely the destination itself that creates personal troubles for the experiencers. Where each person begins his or her journey, and at which social points he or she returns to tell the story, are also crucial determinants of the experiences of both self and social acceptance. In other words, all six steps, from first to last, shape and determine a sense of personal safety and the public response that affirms or undermines it.

\section{References}

Barrett, W. (1986). Death-bed visions: The psychical experiences of the dying. Wellingborough, England: Aquarian Press. (Original work published 1926)

Burgess, O. O. (1908). Hallucinations experienced in connection with dying persons. Journal of the Society for Psychical Research, 13, 308-311.

Dale, L. A. (1952). Spontaneous cases. Journal of the American Society for Psychical Research, 46, 31-35.

Fenwick, P., and Fenwick, E. (1995). The truth in the light: An investigation of over 300 near-death experiences. London, England: Headline.

Glaser, B. G., and Strauss, A. L. (1971). Status passage. London, England: Routledge and Kegan Paul.

Gurney, E., Myers, F. W. H. and Podmore, F. (1886). Phantasms of the living (2 vols). London, England: Trübner.

Kellehear, A. (1990). The near-death experience as status passage. Social Science and Medicine, 31, 933-939.

Kellehear, A. (1996). Experiences near death: Beyond medicine and religion. New York, NY: Oxford University Press.

Moody, R. A. (1999). The last laugh: A new philosophy of near-death experiences, apparitions, and the paranormal. Charlottesville, VA: Hampton Roads.

Osis, K. (1961). Deathbed observations by physicians and nurses. New York, NY: Parapsychology Foundation. 